\title{
Investigating the Relationship between Academic Procrastination and Academic Efficiency in Medical Students of Mashhad University
}

\author{
Prof. Dr. Seyed Saeid Zamanieh Shahri, MD*, Prof. Dr. Sonia Sayyedalhosseini, MD* \\ Faculty Members in California Northstate University, CNSU-University Professors in Losrios Community College District, USA
}

*Corresponding authors: Prof. Dr. Seyed Saeid Zamanieh Shahri, MD, Faculty Member in California Northstate University, CNSU-University Professor in Losrios Community College District, USA, Tel: (916) 724-9485; E-mail: saeid.zamanieh@cnsu.edu; zamanis@flc.losrios.edu

Prof. Dr. Sonia Sayyedalhosseini, MD, Faculty Member in California Northstate University, CNSU-University Professor in Losrios Community College District, USA, Tel: (916) 517-8294; E-mail: sonia.sayyedalhosseini@cnsu.edu; sayyeds@flc.losrios.edu

Received: 03 Dec, 2020 | Accepted: 28 Jan, 2021 | Published: 04 Feb, 2021

Citation: Shahri SSZ, Sayyedalhosseini S (2021) Investigating the Relationship between Academic Procrastination and Academic Efficiency in Medical Students of Mashhad University. J Psychiatry Ment Health 6(1): dx.doi.org/10.16966/2474-7769.139

Copyright: @ 2021 Shahri SSZ, et al. This is an open-access article distributed under the terms of the Creative Commons Attribution License, which permits unrestricted use, distribution, and reproduction in any medium, provided the original author and source are credited.

\section{Abstract}

Introduction: Academic procrastination is common among students during their studies and graduation and it means the tendency to postpone studying responsibility. The aim of this study was to investigate the relationship between academic procrastination and academic efficiency in medical students of Mashhad University.

Materials and Methods: A total of 433 medical students in internship and physiopathology were included in the study. The Rothblum Student Postponement Scoreboard was used to evaluate the purpose of procrastination and the Wood and Lock Schedule was used to evaluate and determine individual effectiveness. Data were then analyzed using statistical tools.

Results: 267 students (62.5\%) were girls and 162 students (37.5\%) were boys, and $3.8 \%$ were single and $36.9 \%$ were married. The average academic efficiency was 90.7 with maximum 153 and minimum 46. There was a statistically significant relationship between academic procrastination and academic efficiency $(p<0.05)$. Postponement of education significantly reduced academic efficiency, and academic achievement was more affected in girls and married couples by academic deferment.

Conclusion: There is a significant relationship between academic procrastination and academic efficiency. Decreasing academic procrastination can be effective in improving academic efficiency and vice versa.

Keywords: Academic procrastination; Academic efficiency; Medical student

\section{Introduction}

Postponement: This term means a pattern of behavior related to academic achievement. According to Senecal theory, procrastination means that a person knows and may want to finish his/her education in a certain period of time but fails. Others have defined this trait as a tendency to delay education due to levels of anxiety and stress [1].

The variable associated with procrastination individually is academic effectiveness. Bandura defines efficiency as the judgment of individuals about their ability to organize the actions required for a particular action. Individual success depends not only on skills but also on willingness to perform tasks properly. A person with constant knowledge and abilities can be seen due to fluctuations in their beliefs that people lack the necessary skills or weak beliefs and therefore low efficiency [2]. Based on Bandura theory, efficiency is effective through cognitive, emotional and behavioral actions. For example, efficiency affects the choice of behavior. People are more inclined to reach challenging situations and situations that they can overcome well and successfully and avoid being in situations that are beyond their ability [2].

High-efficiency people tend to see successful scenarios that can lead them to better performance. People with low efficacy often relate to failure scenarios that impair their performance. Expecting success or failure can affect the amount of effort people put into dealing with obstacles. People who are confident in their ability to do a particular task work harder against obstacles and challenges, while people who doubt their abilities doesn't work hard against obstacles or even they may make their own efforts but they leave it unfinished and accept a conservative solution [2]. Procrastination in Latin has two parts: "pro" means "forward" and "crastinus" means "tomorrow" and literally means until tomorrow. Synonyms included negligence and hesitation. Procrastination is unnecessary action due to habitual carelessness, laziness, perfectionism or even tendency to postpone [2]. Although the definition of procrastination has wide range from delays 
in starting or completing a course of action [2] to delays in continuity of action with mental distress [3] and irrational delays in behavior [4], but overall it is defined as delaying or postponing an action that one has to do and as a result experiences a level of anxiety caused by procrastination [4].

The literal meaning of procrastination is to postpone things to another day. Most research has emphasized the relationship between procrastination and gender; but they have yielded contradictory results. In some studies, no difference was reported between the two sexes, while in others, the level of women's and in others, the level of men's procrastination was reported higher. Other studies have attributed differences between the sexes to mediating variables such as self-control and parental independence. In male students, for example, it predicts psychological individualization, self-control, and academic procrastination. But in the case of girls, putting aside emotional conflict with their parents rather than individualizing their prediction is academic restraint and procrastination. Probably no academic assignment is free of motivation and procrastination. It is not surprising, however, that the key to academic success depends on a strong sense of efficiency or belief in the ability to do well within the expected time frame. The two constructs of academic efficiency and procrastination definitely affect academic performance. In a study on academic achievement on the three variables of perfectionism, general efficiency and procrastination that were considered in relation to each other, the results showed that perfectionism as one of the mediating variables of self-efficacy and procrastination is associated with positive and negative effects that can be seen in psychological studies of this fluctuation [3].

However, other evidence suggests that homework self-efficacy is poorly associated with procrastination. By correlation analysis, Klassen RM, et al., studies [5] showed that procrastination was inversely related to the mean academic grade and academic efficiency for self-regulation. That self-regulation was an important predictor of procrastination. In this study, academic self-efficacy was a poor predictor of procrastination, while self-efficacy for self-regulation emerged as a factor influencing academic procrastination [5].

Many people postpone what they know they have to do until tomorrow. This phrase, while simple and seemingly small, is one of the most important issues that has a psychological moral root and is called procrastination in expressing the problem. Procrastination is more than not doing things. As Alice's HE, et al., [6] theory it is a syndrome of the individual that the task that is decided to be performed, and that task can at least have consequences for the individual in the future, is left to the future for no reason. At the same time the individual blames him/herself for it [6].

So, the aim of this study was to investigate the relationship between academic procrastination and academic efficiency in medical students of Mashhad Medical University and answering to the following questions;

I. Was there a relationship between procrastination and academic efficiency in medical students of Mashhad Medical University?

II. Was there a relationship between non-procrastination and academic efficiency in medical students of the Mashhad Medical University with regard to gender?

III. Was there a relationship between non-procrastination and academic efficiency in medical students of Mashhad Medical University according to the level of education?

\section{Materials and Methods}

General purpose of this study was determining the relationship between procrastination and educational efficiency in medical students of Mashhad Medical University.

In this study, two variables (academic procrastination, academy efficiency) are examined by using appropriate tools. Type of study was descriptive-analytical. Research sample size calculated by the following formula; $\mathbf{n}=\frac{N}{1+N e^{2}}$, without Removal criteria. Sampling method was stratified random.

Out of the 225 total number of intern students, with a $5 \%$ error, 144 were selected. From the 168 total number of intern students, with $5 \%$ error, 119 were selected. From the total of 293 basic science and physiopathology students with 5\% error, 170 were selected. Methods and tools of data collection:

I. Brief demographic information questionnaire had designed to determine gender, marital status, and educational level variables. Its questionnaire is attached in Appendix A.

II. Procrastination Assessment Scale-Students (PASS) of Solomon LJ and Rothblum ED [7]. Its questionnaire attached in Appendix B.

III. Wood and Locke's Educational Self-Efficacy Scale (ASE) [8]. Its questionnaire attached in Appendix C.

Because this study was conducted on a sample of university students and academic performance is the main focus so, Solomon LJ and Rothblum ED [7]. Student Postponement Scoreboard was used to assess participants delayed goals.

\section{PASS}

The first part of the PASS was related to causes of cognitive behaviors for the procrastination process, and it consists of 18 options that assess the prevalence of the procrastination process in six academic activities: writing a final semester report sheet for exams, continuing weekly studies, academic admissions, attendance task, and academic activities. Examples of doing academic admissions include getting an ID card, enrolling in classes, and filling out training forms. Attendance task is to meet with professors and professors and how to deal with the tutor. Participants are classified based on a score of 5 points they get for postponing their activities. This is different from never postponing (a) score to always postponing (e) score. Participants were also surveyed to see if procrastination was causing a problem, from never having a problem (a) score to always having a problem (e) score.

Finally, participants are categorized according to the degree of reduction of their intentions to postpone their work; from I do not want to reduce (a) score until I clearly intend to reduce it (e) score. PASS is scored by placing a score and value for each question such as $d=4, c=3, b=2, a=1$ and $e=5$. The first two questions of each of the 6 Deferred Degree Tables are then summed for an overall score that varies from 12 to 60 . A highest score is for the person that postpones the task the most (Figure 1). Many researchers have reported an alpha coefficient for delayed intensity, such as 0.75 [9], 71\% [10], and $84 \%[11]$.

Ferrari JR [9], evaluated 6 weeks and reported a correlation coefficient of 0.74 for prevalence [9].

\section{ASE}

According to the original Bundura model of Self-efficacy, a special table is needed to measure and determine Self efficacy in academic areas. Therefore, to evaluate the academic self-efficacy of the participants, the 


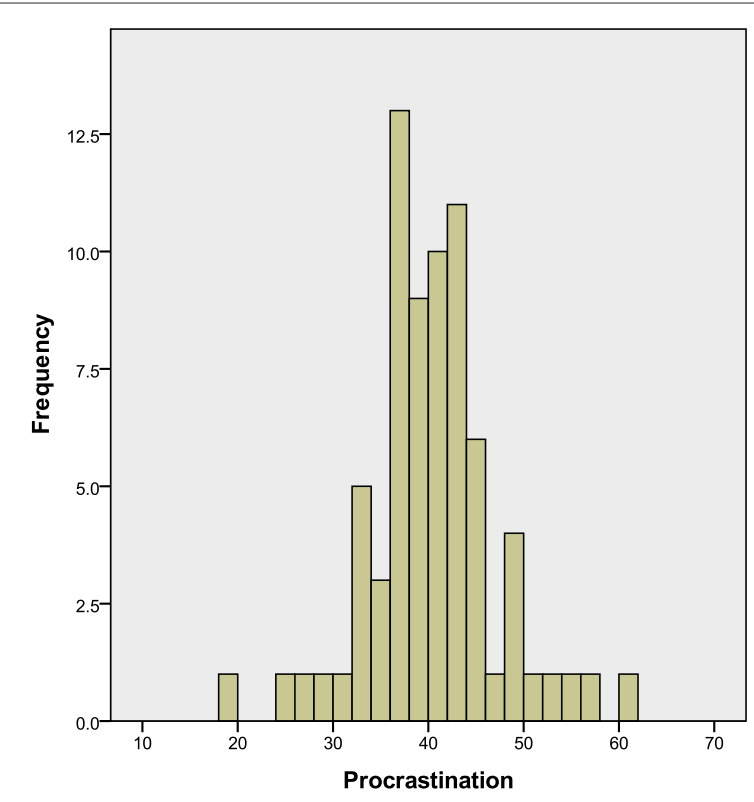

Figure 1: Frequency of procrastination among sample groups.

modified model of Self-efficacy, Locke and Wood table was used (ASE: 1987) [8]. ASE is an old self-efficacy measurement method used to assess the magnitude or levels at which people believe they are capable of doing work, or the level of self-confidence at which people are able to do work $[2,8]$. ASE evaluates seven areas of academic performance, that include focusing to the course in the class, memorizing ability, focus on the exam session, comprehension, explanation important points, ideas and taking notes. Options include 4 to 5 performance levels per area, for example focusing on at least $50 \%$ (or $70 \%, 90 \%$ or $100 \%$ ) of class time or $50 \%$ (or $70 \%, 90 \%$ or $100 \%$ ) of events and Imaginations. Participants are identified for their ability to perform at any level of performance, and their level of self-confidence ranges from completely insecure (0) to completely confident [12]. Maurer TJ and Pierce HR [13] in 1998 made another type of ASE table with some changes in the previous one. For example the Participants were given key options to choose for their belief of their personal ability level from "I can do $10 \%$ of comprehension and memorizing ability" to $100 \%$. And rewrite again all academic performance task score. A simple form of this model was used in this study. Participants were asked about a 5 -point table that if strongly disagreed " 1 " score, with strongly agreeing " 5 " score. Range of scores varies from 5 to 25 . The overall score of the table was obtained by combining the scores below the table with the overall scores, which ranged from 33 to 165 . The simplicity of the old model with the new model of the table was evaluated by its accuracy and predictive value, but no significant difference in average scores of these two models was determined [13].

\section{Analysis method}

The obtained results are described descriptively in the form of tables and statistical graphs. Also, in the data analysis section, the fit of Pearson correlation coefficient regression model with t-test was used to evaluate the significance of this coefficient and partial correlation coefficient. The statistical software SPSS 18 was used with a test error level of at least $5 \%$. Ethical considerations were deliberated by keeping the information secret.

\section{Research methods}

In a descriptive-analytical study, after sampling, medical students of Mashhad University, we entered the study. PASS and ASE were the research tools. Students examined in three groups: Physiopathology and Basic Sciences, Internship group and Intern group. The questionnaire placed at the student's discretion and they completed the forms. Then the information was collected and by using SPSS 18 statistical software and 5\% test level, data analyzed (Pearson regression correlation tests) $[14,15]$ and presented by using mean, median and standard deviation. The results expressed descriptively in the form of tables and statistical graphs.

\section{Results and Discussion}

Procrastination means a pattern of behavior associated with academic achievement.

Individual success depends not only on one's skills and abilities, but also on one's beliefs in the proper and effective use of those skills in a certain time period. A person with constant knowledge and abilities can perform poorly, well or moderate due to fluctuations in their beliefs about their abilities. Poor performance can be seen when people lack the necessary skills or beliefs and therefore low efficiency happened. High-efficiency people tend to see successful scenarios that can lead them to better performance.

People with low performance often associate themselves with failure scenarios that impair their performance. The distribution of victory or defeat can affect the amount of effort people put in facing obstacles.

People who are confident in their ability to do a particular task work harder against obstacles and challenges, while people who doubt their abilities may work less against obstacles or give up working and accept a conservative solution [2]. In this study, we tried to investigate the relationship between procrastination and academic efficiency of medical students of Mashhad Medical University.

In the study, out of 433 medical students who were given the questionnaire, $272(62.5 \%)$ were girls and 162 (37.5\%) were boys (Figure 2). The highest number of sample students was in the Intern group. Basic science and physiopathology students with 144 students $(33.2 \%)$ were in the next rank and the lowest number were

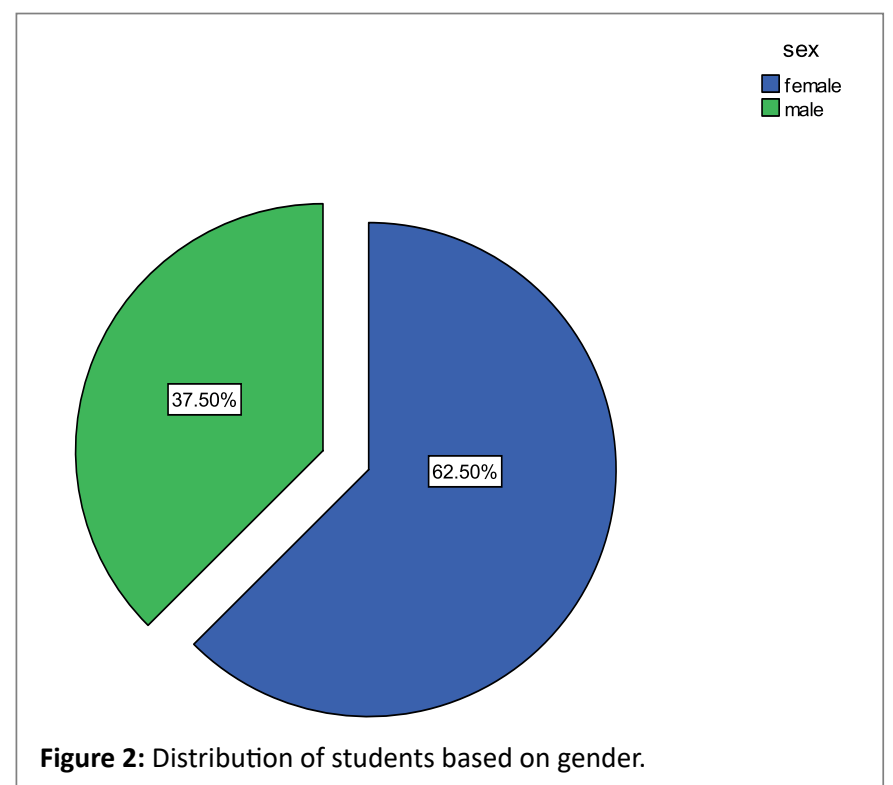


related to internship students with 119 students (27.8\%). Out of 433 students, 276 students were single and 157 students were married. The lowest academic procrastination was 19 months and the highest procrastination was 60 months.

One of the variables in this study is gender. Distribution of students based on gender was showed in the figure 2 .

The other variable is education level in medical school; (Table 1).

Group\# 1- Basic science and physiopathology students (First 3 years in medical school).

Group\# 2- Internship (stager) students (year $4^{\text {th }}$ and $5^{\text {th }}$ ).

Group\# 3- Intern students (year $6^{\text {th }}$ and $7^{\text {th }}$ ).

In this study, the lowest and highest academic efficiencies were 46 and 153, respectively, with an average of 90.7 and standard deviation of 28.64. Due to the fact that both the variables of procrastination and academic efficiency were slightly discrete, so the correlation coefficient was used to express the existence or non-relationship between them. Due to the high sample size in this study, Pearson correlation coefficient was used. The correlation coefficient between the variables of academic procrastination and academic efficiency was calculated to be $433 \%$ and considering a p-value equal to $000 \%$ which was significant at the level of one percent error. The negative value of the correlation coefficient indicates that the relationship between procrastination and academic efficiency is an inverse relationship; that means, as the amount of academic efficiency increases, the amount of academic procrastination decreases. On the other hand, due to the significant relationship between the variables of academic procrastination and academic efficiency based on regression, if the academic procrastination of one unit increases, the amount of academic efficiency decreases by 1.863 units. The tables below showed the Pearson correlation (Table 2) coefficient (Table 3 ) and the corresponding p-value.

Academic performance in girls was more affected by academic procrastination; that means, by increasing the number of units by postponing education, the efficiency of the girls group decreased more than the boys group.

Most research has emphasized the relationship between procrastination and gender; however, contradictory results have been obtained. In some studies, no difference has been mentioned between the two sexes. While in some, the level of female procrastination has been reported and in others, the level of male procrastination has been reported higher, other studies have attributed the difference between the sexes to mediating variables such as self-control and parental independence [16]. In male students, for example, it

Table 1: Frequency of students in different grade of medical school.

\begin{tabular}{|c|c|c|c|c|c|}
\hline \multicolumn{6}{|c|}{ Education } \\
\hline & & Frequency & percent & $\begin{array}{c}\text { Value } \\
\text { percentage }\end{array}$ & $\begin{array}{l}\text { Cumulative } \\
\text { frequency } \\
\text { percentage }\end{array}$ \\
\hline \multirow[t]{4}{*}{ Valid } & $\begin{array}{l}\text { Basic } \\
\text { science and } \\
\text { physiopathology } \\
\text { students }\end{array}$ & 144 & 33.26 & 33.26 & 33.26 \\
\hline & $\begin{array}{l}\text { Internship } \\
\text { (stager) students }\end{array}$ & 119 & 27.48 & 27.48 & 60.74 \\
\hline & Intern students & 170 & 39.26 & 39.26 & 100.0 \\
\hline & Total & 433 & 100.0 & 100.0 & \\
\hline
\end{tabular}

Table 2: Correlation between academic procrastination and efficiency.

\begin{tabular}{|c|c|c|c|}
\hline \multicolumn{4}{|c|}{ Correlations } \\
\hline \multicolumn{2}{|c|}{} & $\begin{array}{c}\text { Academic } \\
\text { Procrastination }\end{array}$ & $\begin{array}{c}\text { Academic } \\
\text { Efficiency }\end{array}$ \\
\hline \multirow{2}{*}{$\begin{array}{c}\text { Academic } \\
\text { Procrastination }\end{array}$} & Pearson correlation & 1 & $-0.443^{* *}$ \\
\cline { 2 - 4 } & p-value (2-tailed) & & 0.000 \\
\cline { 2 - 4 } & $\mathrm{N}$ & 433 & 433 \\
\hline \multirow{2}{*}{$\begin{array}{c}\text { Academic } \\
\text { Efficiency }\end{array}$} & Pearson correlation & $-0.443^{* *}$ & 1 \\
\cline { 2 - 4 } & p-value (2-tailed) & .000 & \\
\cline { 2 - 4 } & $\mathrm{N}$ & 433 & 433 \\
\hline \multirow{2}{*}{$* *$. Correlation is significant at the 0.01 level (2-tailed). } \\
\hline
\end{tabular}

Table 3: Academic procrastination coefficients with efficacy.

\begin{tabular}{|c|c|c|c|c|c|c|}
\hline \multicolumn{7}{|c|}{ Coefficients } \\
\hline & \multirow{2}{*}{ Model } & \multicolumn{2}{|c|}{$\begin{array}{l}\text { Non-standard } \\
\text { coefficients }\end{array}$} & \multirow{2}{*}{\begin{tabular}{|c|}
$\begin{array}{c}\text { Standard } \\
\text { coefficients }\end{array}$ \\
Beta \\
\end{tabular}} & \multirow{2}{*}{$t$} & \multirow{2}{*}{ p-value } \\
\hline & & $\begin{array}{l}\text { Line } \\
\text { slope }\end{array}$ & $\begin{array}{c}\text { Standard } \\
\text { error }\end{array}$ & & & \\
\hline \multirow[b]{2}{*}{1} & Constant & 164.676 & 18.135 & & 9.080 & 0.000 \\
\hline & $\begin{array}{l}\text { Academic } \\
\text { Procrastination }\end{array}$ & -1.863 & 0.450 & -0.443 & -4.137 & 0.000 \\
\hline
\end{tabular}

predicts psychological individualization, self-control, and academic performance. But in the case of girls, the exclusion of emotional conflict with the parents rather than individualization was a predictor of self-control and academic procrastination, and for example, in the individual study, no difference in terms of gender was reported in the rate of procrastination $[17,18]$.

In Milgram NA, et al., study, anxiety was weakly associated with delay itself; it meant that anxiety was not the main reason of procrastination. Delay was significantly associated with perceptual ability to perform academic tasks and hope to change procrastination behavior. Students postponed annoying homework more than pleasant ones and they felt more confused and anxious about unpleasant homework, and they made more reasons for procrastination of frustrating homework than the pleasant one $[19,20]$.

In this study, the interest in reducing procrastination in the students evaluated more with the ability of self-perceive to perform tasks in a certain time than to the wasted time for procrastination itself.

This study was resulted that students procrastinated unpleasant and frustrating homework more than the pleasant one unlike our study that focused more on the procrastination due to perception of students from their abilities and decreasing the academic efficiency in consequence.

In the study of Onwvegbuzie, concluded that academic procrastination has been associated with both fear of failure and task aversiveness. Onwvegbuzie and his researchers have reported that most undergraduate and graduate students delay academic tasks. Among the latter, a large proportion report procrastination in writing term papers [10]. Such procrastination may originate from and lead to anxiety about writing so the present purpose was to investigate the relationship between scores on Daly JA and Miller MD 1975 [21] 
Writing Apprehension Test and on the two dimensions, i.e., fear of failure and task aversiveness, of Solomon LJ, and Rothblum ED 1984 Procrastination Assessment Scale-Students [7]. Participants were 135 graduate students of varied disciplinary backgrounds. Correlations between writing apprehension and academic procrastination stemmed from fear of failure and task aversiveness [10]. In this study, as in our study, academic procrastination due to fear of inability and fear of failure were correlated.

In Ozer BU [9] study, 2784 students (363 women, 421 men; M age $=20.6$ years, $\mathrm{SD}$ age $=1.74$ years) completed the validated Turkish Procrastination Assessment Scale-Students. The results were that $52 \%$ of students self-reported frequent academic procrastination, with male students reporting more frequent procrastination on academic tasks than female students, but significantly female students reported academic procrastination, more because of fear of failure; male students reported more academic procrastination as a result of risk taking and rebellion against control than did female students [9]. This study confirmed the results of Onwvegbuzie study as well as our study in explanations the reasons of academic procrastination.

In Hossein Chari's study, as in this study, regression statistical method was used to analyze information about academic procrastination. In Hossein Chari's study, it was concluded that there is a significant difference between the mean of self-regulatory strategies for learning, cognitive strategies and academic procrastination in girls and boys. In this way, girls have more self-regulation and cognitive strategies and less academic procrastination than boys [22]. These findings were similar to the findings of Ozer BU study [9] as well as our study in the sense that male students reporting more frequent procrastination on academic tasks than female students and findings of Pearson correlations showed a positive association between fear of failure and academic procrastination, and a negative association between subscales of self-regulation and academic procrastination. Also, linear regression analyses showed that fear of failure and responsibility predicts academic procrastination. As a conclusion, in order to reduce procrastination, some interventions can be delivered by handling in students' fear of failure and self-regulation [22].

In Sepehrian's F study, the mean score of procrastination in homework preparation and the total score of academic procrastination in boys were higher than girls. In other dimensions of procrastination, no significant difference was observed between the two groups [23].

In our study, the average academic efficiency of basic science and physiopathology students were more than intern group and intern group efficiency was more than internship group. Based on Fisher's test and the $p$ value, which was zero, it was concluded that the average academic performance in these three groups was not equal, and to answer the question of which group had a broader different average than the others, Duncan's table 4 [24] was used. According to this table, the average academic efficiency of basic and intern students was equal and only the average academic efficiency of internship students was different from the other two groups.

It is possible to reduce procrastination by educating self-regulation learning strategy to students and help them reduce the fear of failure $[25,26]$. As showed in previous studies, self-regulation learning strategies might reduce academic procrastination. As mentioned, procrastination is a common problem in different societies especially in university students. Research findings by Zarrin SA [27] on 2019 showed that high academic procrastination related to low academic achievement in students. Thus, it can be concluded that for academic performance to be successful, it is essential to address the problem of
Table 4: Frequency of academic efficiency in different grade of medical school.

\begin{tabular}{|c|c|c|c|c|}
\hline \multicolumn{5}{|c|}{ Academic Efficiency } \\
\hline \multicolumn{5}{|l|}{ Duncan [24] } \\
\hline \multirow{2}{*}{\multicolumn{2}{|c|}{ Education level }} & \multirow{3}{*}{$\begin{array}{c}\mathbf{N} \\
144\end{array}$} & \multicolumn{2}{|c|}{ Subset for alpha $=0.05$} \\
\hline & & & 1 & 2 \\
\hline \multirow{4}{*}{$\begin{array}{c}\text { Dimension } \\
1\end{array}$} & $\begin{array}{l}\text { Internship } \\
\text { (stager) group }\end{array}$ & & 73.35 & \\
\hline & Intern group & 119 & & 102.92 \\
\hline & $\begin{array}{l}\text { Basic \& } \\
\text { Physiopathology } \\
\text { group }\end{array}$ & 170 & & 115.67 \\
\hline & p-value & & 1.000 & 0.312 \\
\hline
\end{tabular}

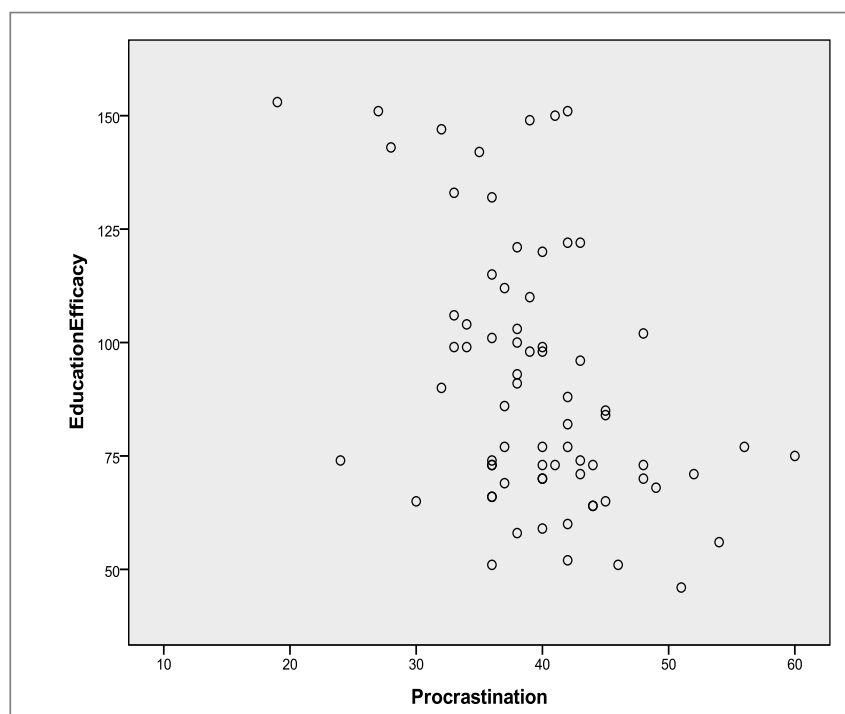

Figure 3: Distribution of two variables of academic procrastination and academic efficiency.

procrastination among university students. In severe cases of academic procrastination in students, they need to be referred to psychologists and counselors for treatment, and the findings so far suggest that cognitive behavioral therapy reduced procrastination more than the other types of interventions [28].

\section{Conclusion}

There is a significant relationship between academic procrastination and academic efficiency reversely (Figure 3 ). Decreasing academic procrastination can be effective in improving academic efficiency and vice versa.

\section{References}

1. Burka J, Yuen LM (1983) Procrastination: Why you do it, What to do about it. $1^{\text {st }}$ Edition, Hachette Books 450-457.

2. Bandura A (1986) Social Foundations of Thought and Action: A Social Cognitive Theory. $2^{\text {nd }}$ Edition, Englewood Cliffs, Prentice Hall 121-126.

3. Von Ah D, Ebert S, Ngamvitroj A, Park N, Kang DH (2004) Predictors of health behaviors in college students. J Adv Nurs 48: 463-474. 
4. Erik TH, Linda JL (2004) Attachment relationships and health behavior: The mediational role of self-esteem. Psychology and Health 19: 515-526.

5. Klassen RM, Krawchuk L, Rajani S (2008) Academic procrastination of undergraduates: Low self-efficacy to self-regulate predicts higher levels of procrastination. Contemporary Educational Psychology 33: 915-931.

6. Alice HE, Wendy W (2012) Social role theory. In: Van Lange PAM, Kruglanski AW, Higgins ET (eds) Handbook of theories of social psychology 458-476.

7. Solomon LJ, Rothblum ED (1984) Procrastination Assessment Scale Students (PASS). Journal of Counseling Psychology 31: 503-509.

8. Wood RE, Locke EA (1987) The Relation of Self-Efficacy and Grade Goals to Academic Performance. Educational and Psychological Measurement 47: 1013-1024.

9. Ferrari JR, Ozer BU, Demir A (2009) Chronic procrastination among Turkish adults: exploring decisional, avoidant, and arousal styles. $J$ Soc Psychol 149: 402-408.

10. Sheila B, Renee RD (2000) Putting off until tomorrow what is better done today: Academic procrastination as a function of motivation toward college work. Journal of Social Behavior and Personality 15 $15-34$

11. Onwvegbuzie AJ, Collins KM (2001) Writing apprehension and academic procrastination among graduate students. Percept Mot Skills 92: 560-562.

12. Woodruff S, Cashman J (1993) Task, Domain, and General Efficacy: A Reexamination of the Self-Efficacy Scale. Psychological Reports 72 : 423-432.

13. Maurer TJ, Pierce HR (1998) A comparison of Likert scale and traditional measures of self-efficacy. J Appl Psychol 83: 324-329.

14. Senécal C, Koestner R, Vallerand RJ (1995) Self-Regulation and Academic Procrastination. J Soc Psychol 135: 607-619.

15. Esther RD, Laura SJ, Janice M (1986) Affective, cognitive and behavioral differences between high and low procrastinators. Journal of Counseling Psychology 33: 387-394.

16. SPSS Tutorials: Pearson Correlation. Kent State University.
17. Pychyl TA, Coplan RJ, Reid PAM (2002) Parenting and procrastination: Gender differences in the relations between procrastination, parenting style and selfworth in early adolescence. Personality and Individual Differences 33: 271-285.

18. Balkis M, Duru E (2017) Gender Differences in the Relationship between Academic Procrastination, Satifaction with Academic Life and Academic Performance. Electronic Journal of Research in Educational Psychology 15: 105-125.

19. Milgram NA, Gehrman T, Keinan G (1992) Procrastination and emotional upset: A typological model. Personality \& Individual Differences 13: 1307-1313.

20. Milgram N, Marshevsky S, Sadeh C (1995) Correlates of academic procrastination: discomfort, task aversiveness, and task capability. J Psychol 129: 145-155.

21. Daly JA, Miller MD (1975) The empirical development of an instrument to measure writing apprehension. Research in the Teaching of English 9: 242- 249.

22. Hosseincharri M, Dehghani $Y$ (2007) Predicting the rate of academic procrastination based on self-regulatory strategies in learning. Educational Journal of Research 63-73.

23. Sepehrian F (2011) Academic procrastination and its predictors. Psychologic Journal 27-28.

24. Bewick V, Cheek L, Ball J (2004) Statistics review 9: One-way analysis of variance. Crit Care 8: 130-136.

25. Yao MP (2009) An Exploration of Multidimensional Perfectionism, Academic Self-efficacy, Procrastination Frequency, and Asian American Cultural Values in Asian American University Students. The Ohio State University 52: 1-26.

26. Dietz F, Hofer M, Fries S (2007) Individual values, learning routines and academic procrastination. Br J Educ Psychol 77: 893-906.

27. Zarrin SA, Gracia E, Paixao MP (2020) Prediction of Academic Procrastination by Fear of Failure and Self-Regulation. Educational Sciences: Theory and Practice 20: 34-43.

28. Van Eerde W, Klingsieck K (2018) Overcoming Procrastination? A Meta-Analysis of Intervention Studies. Educational Research Review 25: 73-85. 


\section{Appendix A:}

\section{Brief Demographic Information Questionnaire:}

Age:

Gender:

Female $\square \quad$ Male $\square$

Marital status:

Single $\square \quad$ Married $\square \quad$ Divorced $\square$

Type of diploma:

Experimental science $\square \quad$ Mathematics $\square \quad$ Art, Sports, others $\square$

Residence:

Resident of Mashhad city because of university $\square$ beforehand resident of Mashhad $\square$

Education level:

Basic sciences and physiopathology $\square \quad$ internship (stager) $\square \quad$ intern $\square$

\section{Appendix B:}

Student Deferred Assessment Schedule (PASS: Solomon, Rothblum, 1984) for each of the following activities please specifies the degree to which it is delayed. Choose from "a" to "e" depending on how long you waited until the last minute to do so. Then determine from "a" to "e" depending on how much problem the delay caused. Mark "a" to " $\mathrm{e}$ " to indicate how much you intend to reduce procrastination

I) If you are supposed to write a report, conference text, article, morning report, case report, proposal or thesis;

- How long would you like to procrastinate doing that?
a) Never
b) almost never
c) sometimes
d) almost always
e) always

- How much problem does that delay caused?
a) Never
b) almost never
c) sometimes
d) almost always
e) always

- How much do you intend to reduce procrastination?
a) Never
b) almost never
c) sometimes
d) almost always
e) always

II) Studying for exam;

- How long would you like to procrastinate doing that?
a) Never
b) almost never
c) sometimes
d) almost always
e) always

- How much problem does that delay caused?
a) Never
b) almost never
c) sometimes
d) almost always
e) always

- How much do you intend to reduce procrastination?
a) Never
b) almost never
c) sometimes
d) almost always
e) always

III) Doing your weekly homework;

- How long would you like to procrastinate doing that?
a) Never
b) almost never
c) sometimes
d) almost always
e) always

- How much problem does that delay caused?
a) Never
b) almost never
c) sometimes
d) almost always
e) always

- How much do you intend to reduce procrastination?
a) Never
b) almost never
c) sometimes
d) almost always
e) always 
IV) Doing your academic admissions process such as filling out forms, enrolling in classes and getting an ID card and etc.;

- How long would you like to procrastinate doing that?
a) Never
b) almost never
c) sometimes
d) almost always
e) always

- How much problem does that delay caused?
a) Never
b) almost never
c) sometimes
d) almost always
e) always

- How much do you intend to reduce procrastination?
a) Never
b) almost never
c) sometimes
d) almost always
e) always

V) Executive affairs; meeting with the professor, meeting with the tutor and etc;

- How long would you like to procrastinate doing that?
a) Never
b) almost never
c) sometimes
d) almost always
e) always

- How much problem does that delay caused?
a) Never
b) almost never
c) sometimes
d) almost always
e) always

- How much do you intend to reduce procrastination?
a) Never
b) almost never
c) sometimes
d) almost always
e) always

VI) Academic activities in general;

- How long would you like to procrastinate doing that?
a) Never
b) almost never
c) sometimes
d) almost always
e) always

- $\quad$ How much problem does that delay caused?
a) Never
b) almost never
c) sometimes
d) almost always
e) always

- How much do you intend to reduce procrastination?
a) Never
b) almost never
c) sometimes
d) almost always
e) always

Reasons for postponement; There are some reasons why you postponed the above activities. From each reason for procrastination in the table below, use a phrase that reflects the reason for procrastination of that activity, by Choosing from "a" to "e";

a) Does not fully reflect b) almost does not reflect c) is sometimes reflective d) almost reflects e) Perfectly reflects

\begin{tabular}{|c|c|c|c|c|c|}
\hline Reasons for postponement & $\begin{array}{l}\text { a) does not fully } \\
\text { reflect }\end{array}$ & b) almost does not reflect & c) is sometimes reflective & $\begin{array}{l}\text { d) almost } \\
\text { reflects }\end{array}$ & $\begin{array}{l}\text { e) Perfectly } \\
\text { reflects }\end{array}$ \\
\hline \multicolumn{6}{|l|}{$\begin{array}{l}\text { 1. You were worried that professor } \\
\text { may not approve your work. }\end{array}$} \\
\hline \multicolumn{6}{|l|}{$\begin{array}{l}\text { 2. You waited for your classmate } \\
\text { to complete his/her work and then } \\
\text { help you complete your work. }\end{array}$} \\
\hline \multicolumn{6}{|l|}{$\begin{array}{l}\text { 3. You did not have enough time to } \\
\text { do the job }\end{array}$} \\
\hline \multicolumn{6}{|l|}{ 4.You had a lot of work to do } \\
\hline $\begin{array}{l}\text { 5. You needed information that } \\
\text { you should have asked your } \\
\text { professor, but you did not feel } \\
\text { comfortable dealing with your } \\
\text { professor. }\end{array}$ & & & & & \\
\hline
\end{tabular}




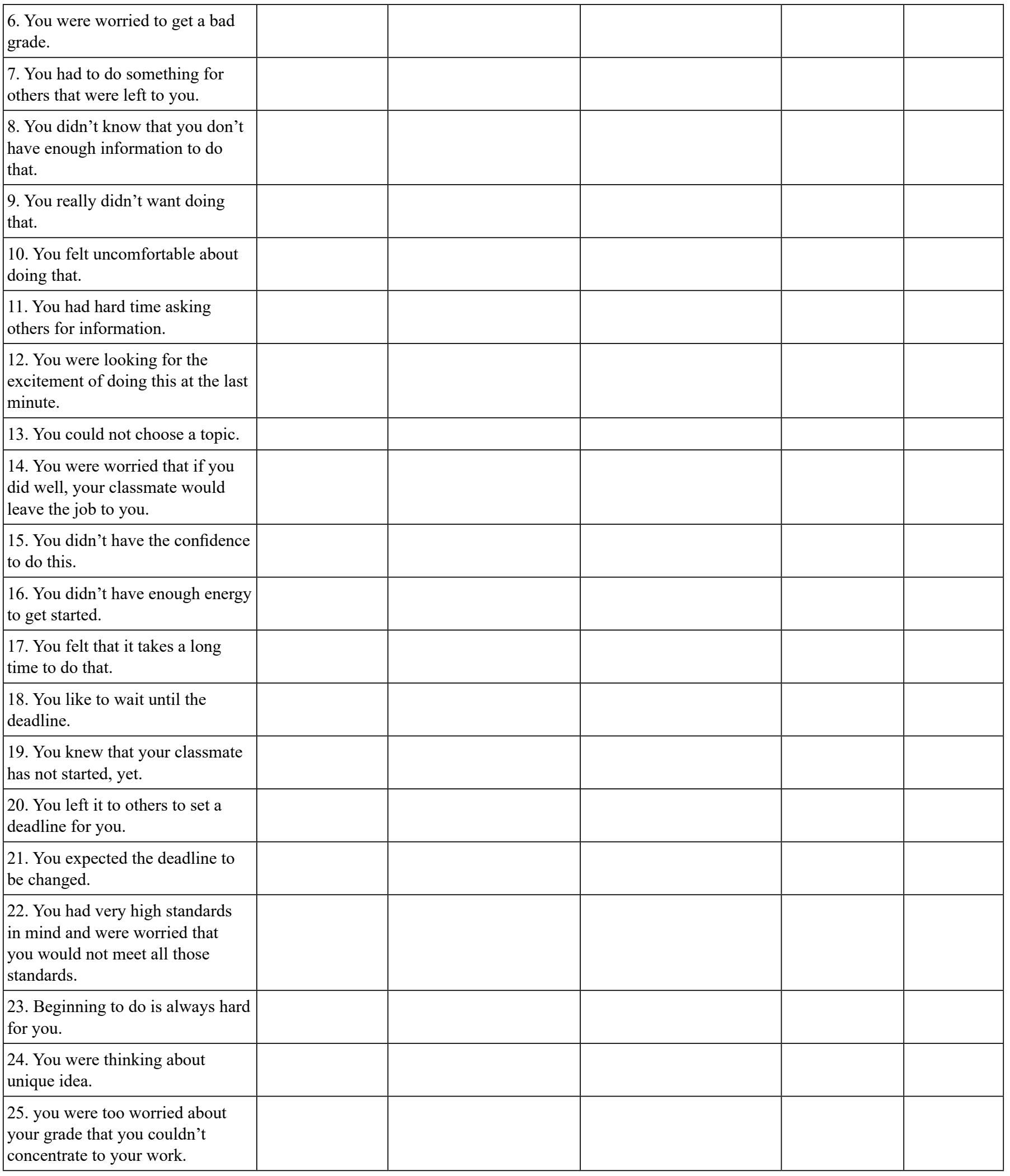

\section{Appendix C:}

Academic Self efficacy scale (ASES, Wood \& Lock, 1987)

These questions are about understanding the ability to do a variety of academic things, such as reading, memorizing, and taking notes. For each case, you are asked if you can judge your ability to do things at different levels of difficulty. 
I) Focus on the class: The part of the class when you feel you have the ability to focus fully on the material being covered.

\begin{tabular}{|c|c|c|c|c|c|}
\hline & Strongly Agree & Agree & Indifferent & Disagree & Strongly Disagree \\
\hline I can concentrate at least $50 \%$ of the class time. & & & & & \\
\hline I can concentrate at least $70 \%$ of the class time. & & & & & \\
\hline I can concentrate at least $90 \%$ of the class time. & & & & & \\
\hline I can focus $100 \%$ of the class time. & & & & & \\
\hline
\end{tabular}

II) Memorizing: Some of the events and perceptions that you feel you can remember and recall if needed.

\begin{tabular}{|l|l|l|l|l|l|}
\hline & Strongly Agree & Agree & Indifferent & Disagree & Strongly Disagree \\
\hline I can remember $60 \%$ of events and imaginations. & & & & & \\
\hline I can remember $70 \%$ of events and imaginations. & & & & & \\
\hline I can remember $80 \%$ of events and imaginations. & & & & & \\
\hline I can remember $90 \%$ of events and imaginations. & & & & & \\
\hline I can remember $100 \%$ of events and imaginations. & & & & & \\
\hline
\end{tabular}

III) Focus on the exam: The part of the test time when you feel you have a complete focus on understanding and answering the test questions.

\begin{tabular}{|c|c|c|c|c|c|}
\hline & Strongly Agree & Agree & Indifferent & Disagree & Strongly Disagree \\
\hline I was completely focused on the test $50 \%$ of the time. & & & & & \\
\hline $\begin{array}{l}\text { I spent } 70 \% \text { of the test time completely focused on the } \\
\text { exam. }\end{array}$ & & & & & \\
\hline $\begin{array}{l}\text { I spent } 90 \% \text { of the test time completely focused on the } \\
\text { exam. }\end{array}$ & & & & & \\
\hline I was $100 \%$ fully focused on the exam time. & & & & & \\
\hline
\end{tabular}

IV) Understanding: Some of the events, ideas, and discussions that you feel are fully understood by you when being presented in a lecture, seminar, or class.

\begin{tabular}{|l|l|l|l|l|l|}
\hline & Strongly Agree & Agree & Indifferent & Disagree & Strongly Disagree \\
\hline I understand $50 \%$ of the concepts when presenting. & & & & & \\
\hline I understand $70 \%$ of the concepts when presenting. & & & & & \\
\hline I understand $90 \%$ of the concepts when presenting. & & & & & \\
\hline I understand $100 \%$ of the concepts when presenting. & & & & & \\
\hline
\end{tabular}

V) Description of events: Some of the events, ideas and topics (introduced in the conference, article, etc.) that you feel you have the ability to describe in full and accurately.

\begin{tabular}{|l|l|l|l|l|l|}
\hline & Strongly Agree & Agree & Indifferent & Disagree & Strongly Disagree \\
\hline I can fully explain $40 \%$ of the events in my own words. & & & & & \\
\hline I can fully explain $60 \%$ of the events in my own words. & & & & & \\
\hline I can fully explain $80 \%$ of the events in my own words. & & & & & \\
\hline I can fully explain $100 \%$ of the events in my own words. & & & & & \\
\hline
\end{tabular}

VI) Distinction between events: The degree to which you feel you can correctly distinguish between more important and less important events.

\begin{tabular}{|l|l|l|l|l|l|}
\hline & Strongly Agree & Agree & Indifferent & Disagree & Strongly Disagree \\
\hline $\begin{array}{l}\text { I have the ability to recognize the most important events } \\
\text { and points in } 50 \% \text { of the time. }\end{array}$ & & & & & \\
\hline $\begin{array}{l}\text { I have the ability to recognize the most important events } \\
\text { and points in } 70 \% \text { of the time. }\end{array}$ & & & & & \\
\hline $\begin{array}{l}\text { I have the ability to recognize the most important events } \\
\text { and points } 90 \% \text { of the time. }\end{array}$ & & & & & \\
\hline $\begin{array}{l}\text { I have the ability to recognize the most important events } \\
\text { and points } 100 \% \text { of the time. }\end{array}$ & & & & \\
\hline
\end{tabular}


VII) Taking notes: The part of the time when you feel you have the ability to write down comprehensible points that emphasize, clarify events and topics.

\begin{tabular}{|l|l|l|l|l|l|}
\hline & Strongly Agree & Agree & Indifferent & Disagree & Strongly Disagree \\
\hline $\begin{array}{l}\text { I have the ability to take comprehensible } \\
\text { notes of } 50 \% \text { of the content. }\end{array}$ & & & & & \\
\hline $\begin{array}{l}\text { I have the ability to take comprehensible } \\
\text { notes of } 70 \% \text { of the content. }\end{array}$ & & & & & \\
\hline $\begin{array}{l}\text { I have the ability to take comprehensible } \\
\text { notes of } 90 \% \text { of the content. }\end{array}$ & & & & & \\
\hline $\begin{array}{l}\text { I have the ability to take } 100 \% \\
\text { comprehensible notes. }\end{array}$ & & & & & \\
\hline
\end{tabular}

VIII) Score: The degrees to which you feel you have the necessary skills to earn different grades in this course.

\begin{tabular}{|l|l|l|l|l|l|}
\hline & Strongly Agree & Agree & Indifferent & Disagree & Strongly Disagree \\
\hline $\begin{array}{l}\text { I can get a score of } 17-20 \text { out of } 20 \text { in this } \\
\text { course. }\end{array}$ & & & & & \\
\hline $\begin{array}{l}\text { I can get at least a score of } 14-16 \text { out of } 20 \\
\text { in this course. }\end{array}$ & & & & & \\
\hline $\begin{array}{l}\text { I can get at least a score of } 12-13 \text { out of } 20 \\
\text { in this course. }\end{array}$ & & & & & \\
\hline $\begin{array}{l}\text { I can get at least a score of } 10-11 \text { out of } 20 \\
\text { in this course. }\end{array}$ & & & & & \\
\hline
\end{tabular}

